Brazilian Journal of Forensic Sciences, Medical Law and Bioethics

Journal homepage: www.ipebj.com.br/forensicjournal

\title{
Homicídio, Suicídio ou Acidente? A Importância da Autópsia Médico-Legal em um Caso de "Cafe Coronary Syndrome"
}

\section{Homicide, Suicide or Accident? The Importance of Forensic Autopsy in a Case of "Cafe Coronary Syndrome"}

\author{
Carlos Henrique Durão, Dina Carpinteiro \\ Instituto Nacional de Medicina Legal, Portugal
}

Received 23 March 2015

Resumo. A determinação da causa mortis e sua etiologia médico legal é fundamental na investigação forense. A autópsia deve esclarecer e elucidar a Justiça no cumprimento de suas decisões. Suicídios podem ser causas de exclusão no pagamento de seguros, e em determinados contratos, o dobro do valor pago em casos de homicídios ou acidentes do que em mortes naturais. O presente artigo mostra um caso de por asfixia resultante de um acidente, onde a vítima embriagada, acabou por sufocar-se ao ingerir um bife inteiro. "Café coronary" foi o termo cunhado por Haugen em 1963 para uma morte e inesperada ocorrida durante uma refeição devido à oclusão das vias aéreas causada por um bife inteiro. Foram afastadas as hipóteses de homicídio e suicídio, que até então existiam. O caso apresenta boa documentação e particular interesse médico legal, corroborando com a importância da autópsia e da abertura de todas as cavidades, incluindo a observação dos órgãos do pescoço.

Palavras-chave: Asfixia; Comida; Cafe coronary; Morte súbita.

Abstract. Determining the cause of death and its forensic etiology is crucial in forensic investigation. The autopsy should clarify and elucidate the Court in its decisions. Suicide may be ground for exclusion in insurance and in certain contracts doubles the amount paid in cases of homicide or accidents opposing natural death. This paper presents a case of death by asphyxiation as the result of an accident where an altered state of consciousness of a drunken victim made him choke with a whole steak. "Cafe 
coronary" was term coined by Haugen in 1963 for sudden and unexpected death occurring during a meal due to accidental occlusion of the airway by food. It were excluded the possibilities of murder and suicide, which hitherto existed. The case provides good documentation and particular medical legal interest, confirming the importance of the autopsy and the opening of all wells, including observation of the neck organs.

Keywords: Asphyxia; Food; Cafe coronary; Sudden death.

\section{Introdução}

O termo "Café coronary" foi descrito por Haugen em 1963 como uma morte súbita e inexplicada que ocorre durante as refeições devida a uma oclusão das vias aéreas por alimentos. Muitas destas vítimas eram pessoas de meia-idade, com muitas comorbidades, e a morte era atribuída a um evento coronariano, como o enfarto do miocárdio. As autópsias mostravam que se tratava de sufocação direta por bolo alimentar ${ }^{1-7}$.

\section{Relato de caso}

Homem de 40 anos, caucasiano, de elevado status social, em processo de divórcio litigioso, com disputa da guarda do filho do casal com a excompanheira. Vários episódios de agressões e ameaças. História recente de grave depressão e alcoolismo. Foi encontrado morto numa Pensão, no chão, em decúbito lateral ao lado da cama, vestindo apenas cuecas, e com a porta entreaberta. As autoridades foram chamadas por um funcionário pela manhã que ao passar pelo quarto se deparou com a porta aberta, a vítima caída no chão junto a várias garrafas de whisky parcialmente vazias e restos de comida espalhados pela cama, que estava desfeita.

A vítima fez o check-in na noite anterior e, segundo informações dos funcionários, encontrava-se muito nervosa e ansiosa, discutindo ao telefone. Solicitou a entrega do jantar na recepção da pensão (bife, arroz e batatas fritas) e subiu para o quarto. A Polícia isolou o local, protegeu as mãos com sacos de papel e encaminhou o corpo para o respectivo Gabinete Médico Legal, após constatar a presença de diversas equimoses. Com a suspeita de um eventual suicídio foram enviados os medicamentos, restos da comida e das bebidas para a respectiva perícia médico-legal. A vítima sofria ameaças de morte e já registrara outros episódios de agressões. 
A autópsia médico-legal constatou no hábito externo a presença de diversas equimoses de limites, contornos e tonalidades diferentes, em diversos segmentos corporais, que de acordo com o espectro equimótico de Legrand du Saulle permitia afirmar que estas, foram produzidas em momentos distintos, 0 que era compatível com as histórias de agressões continuadas (Figura 1(a) e (b)). Também foi constatada na pela uma escoriação semilunar, como as produzidas por deslize ungueal (Figura 2).
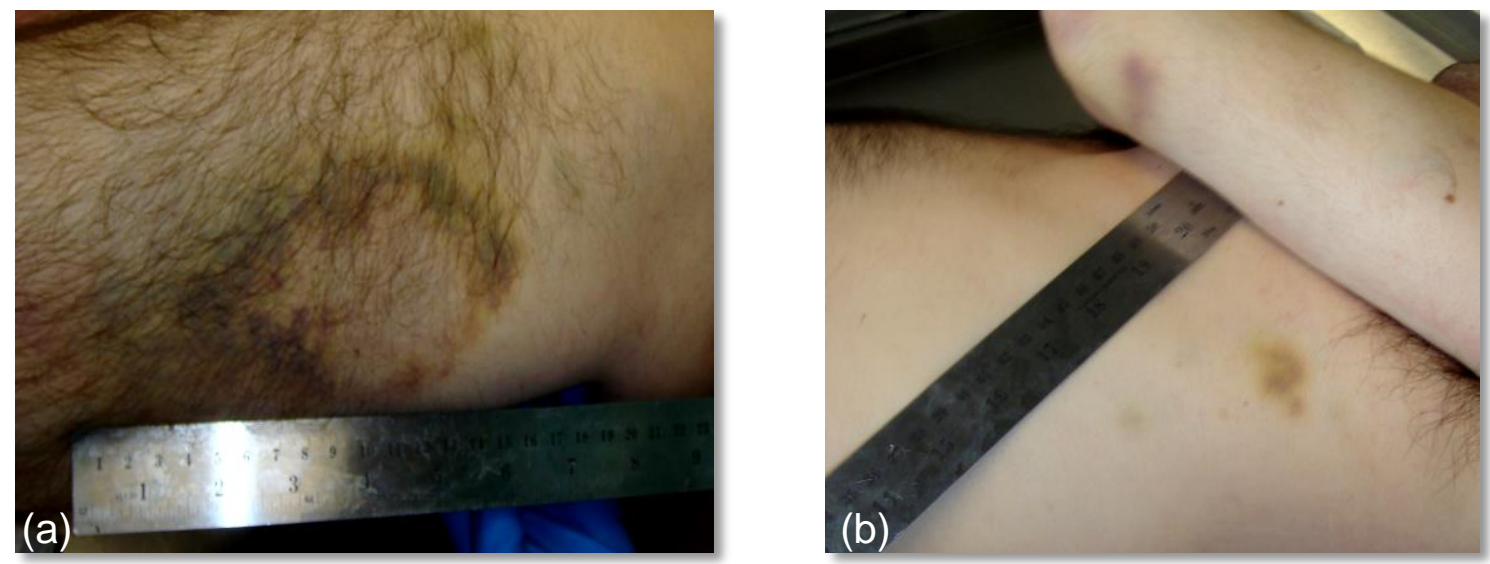

Figura 1. (a) Extensa equimose em processo de reabsorção. (b) Equimoses de tonalidades diferentes, produzidas em momentos distintos.

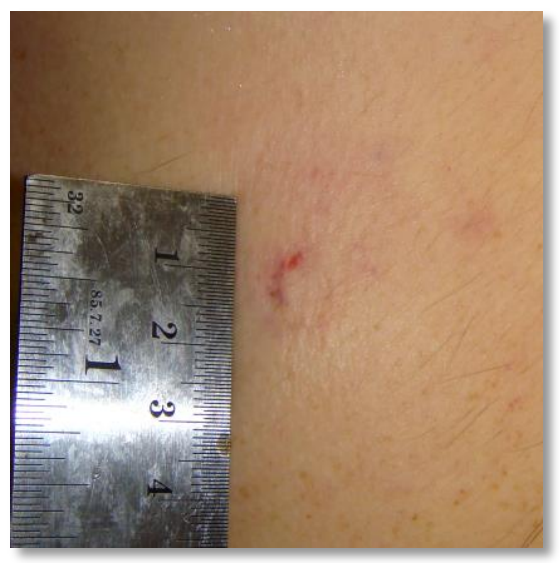

Figura 2. Detalhe de uma escoriação semilunar, como as produzidas por deslize ungueal.

O hábito interno durante a abertura das estruturas dos órgãos do pescoço permitiu a identificação de um desproporcional "bolo de carne" no esófago com oclusão da glote, revelando uma causa de morte asfíxica por oclusão das vias aéreas superiores (Figura 3(a), (b), (c) e (d)). Sufocação direta por engasgamento. O sangue era fluido e escuro e os pulmões apresentavam 
petéquias subpleurais (petéquias de Tardieu). O exame toxicológico foi negativo para drogas de abuso e positivo para álcool etílico.
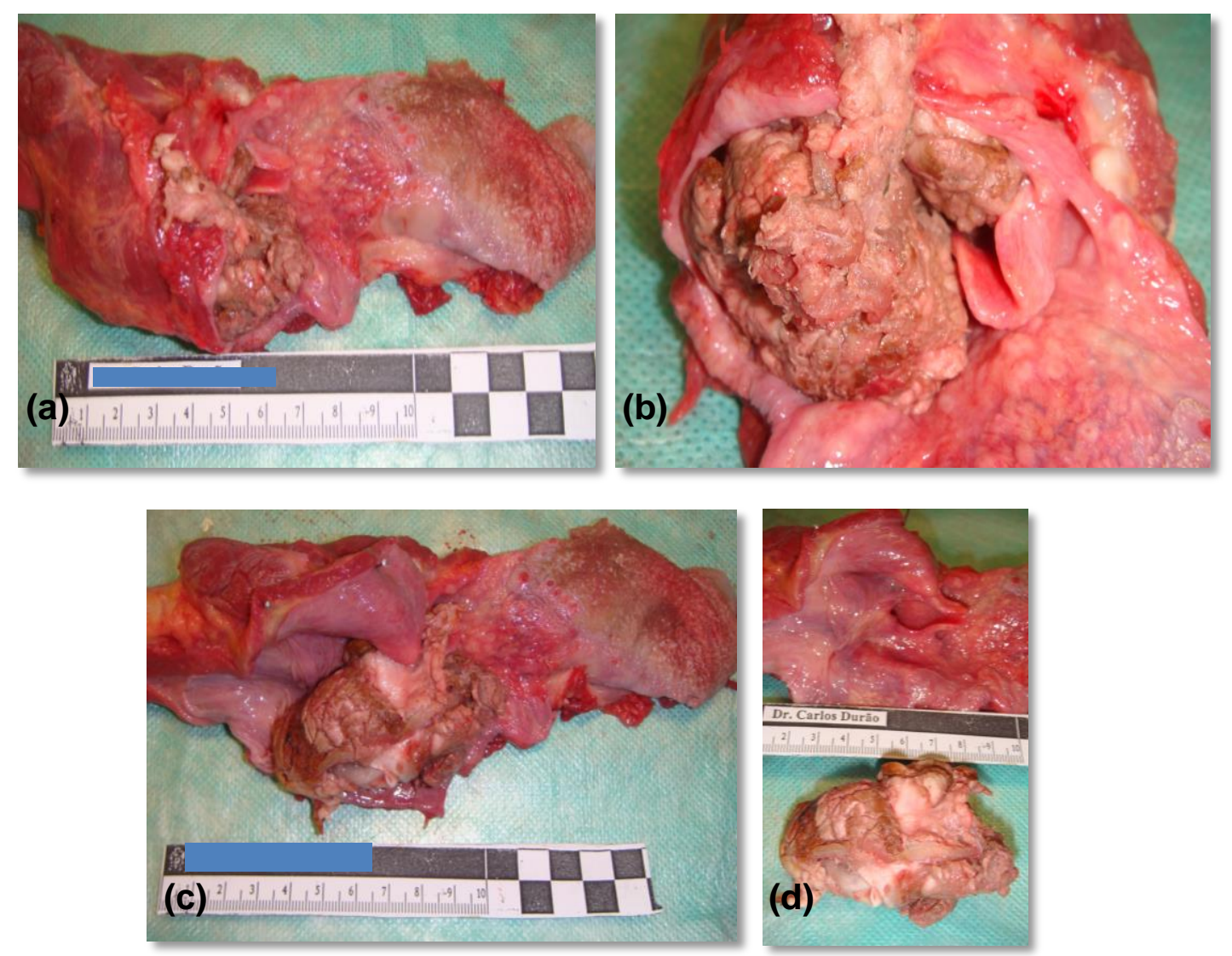

Figura 3. (a), (b), (c), (b) "Bolo de carne" responsável por obstrução das vias aéreas.

\section{Discussão e Considerações finais}

A determinação da causa mortis e sua etiologia médico-legal é fundamental na investigação forense. A autópsia deve esclarecer e elucidar a Justiça no cumprimento de suas decisões. Suicídios podem ser causas de exclusão no pagamento de seguros. Em determinados contratos, o prémio poderá ser 0 dobro do valor em casos de homicídios ou acidentes do que em mortes naturais. Neste caso, a morte por asfixia foi resultante de um acidente, por alteração do estado de consciência, onde a vítima embriagada, acabou por ingerir o bife inteiro ocluindo a glote e sufocando-o. Foram afastadas as hipóteses de homicídio e suicídio, que até então existiam.

Casos como estes são descritos na Literatura como "Café coronary"1-6. A incidência de asfixia por alimentos varia de acordo com a idade em 0,1 a 2 casos por $100.000^{3,8}$. Estudos mostram que os grupos mais vulneráveis não 
são os de meia-idade como se acreditava, mas sim os mais idosos, ou com graves distúrbios mentais ou motores. Doentes com poli ou taquifagia e que não conseguem mastigar ou engolir são mais sucetíveis ${ }^{2,3}$. Em vítimas sem alterações conhecidas as intoxicações alcoólica ou por drogas de abuso são uma importante causa ${ }^{1-6}$.

O mecanismo de morte nestes casos tem sido discutido. Na grande maioria das vezes trata-se uma simples obstrução da via aérea pelo bolo alimentar, porém alguns casos podem ocorrer sem nenhuma evidência de engasgamento, explicado como uma reação reflexa por inibição vagal, ou mesmo por um processo combinado entre ambos ${ }^{3,4}$.

O trabalho alerta para a importância da autópsia médico-legal e a sua correta técnica, com a abertura de todas as cavidades, incluindo um minucioso exame dos órgãos do pescoço e a sua devida documentação fotográfica, além do exame toxicológico e histológico, quando indicados.

\section{Referências}

1. Haugen RK. The café coronary. Sudden deaths in restaurants. JAMA 1963; 186:142-3. crosses

2. Mittleman RE, Wetli CV. The fatal cafe coronary. Foreign-body airway obstruction. JAMA 1982; 247:1285-8. Crossef

3. Wick R, Gilbert JD, Byard RW. Café coronary syndrome-fatal choking on food: An autopsy approach. Journal of Clinical Forensic Medicine 2006; 13:135-8. Frossef

4. Knight B. Suffocation and asphyxia. In: Forensic pathology. Bernard Knight, $2^{\mathrm{a}}$ ed. London. 1996.

5. Spitz WU. Asphyxia. In: Medicolegal Investigation of Death. $3^{\mathrm{a}}$ ed. 1993.

6. Hércules HC. Medicina Legal texto e Atlas. $2^{\mathrm{a}}$ edição. Ed. Atheneu. Rio de Janeiro. 2014.

7. França GV. Medicina Legal. 9ª edição. ed. Guanabara Koogan. Rio de Janeiro. 2011.

8. Berzlanovich AM, Fazeny-Dörner B, Waldhoer T, Fasching P, Keil W. Foreign body asphyxia. A preventable cause of death in the elderly. Am J Prev Med 2005; 28:65-

9. Grosses 